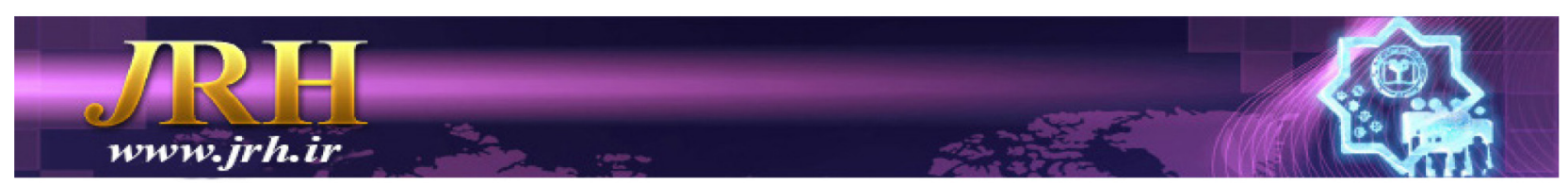

\title{
Adaptation of positive parenting program training based on cultural values and evaluation of its effectiveness in psychological health and interaction of mother with slow paced children \\ Mohammad Ashori ${ }^{1}$, Gholam Ali Afrooz ${ }^{2}$, Ali Akbar Arjmandnia ${ }^{2}$, Masoume Pourmohamadrez-Tajrishi ${ }^{3}$, Bagher Ghobari-Bonab ${ }^{2}$, Seyedeh Somayeh Jalil-Abkenar ${ }^{2}$
}

\author{
Journal of Research \& Health \\ Social Development \& Health Promotion \\ Research Center \\ Vol. 9, No.4, Jul \& Agu 2019 \\ Pages: 284- 293 \\ DOI: 10.29252/jrh.9.4.284 \\ Original Article
}

1. Correspondence to: Department of Psychology and Education of Children with Special Needs, Faculty of Education and Psychology, University of Isfahan, Isfahan, Iran

Email: m.ashori@edu.ui.ac.ir

2. Department of Psychology and Exceptional Children Education, School of Psychology and Educational Sciences, University of Tehran, Tehran, Iran

3. Department of Psychology and Exceptional Children Education, Pediatric Neurorehabilitation Research Center, University of Social Welfare and Rehabilitation Sciences, Tehran, Iran

Received: 11 Feb 2015

Accepted: 24 May 2015

How to cite this article: Ashori M, Afrooz GhA, Arjmandnia AA, Pourmohamadrez-Tajrishi M, Ghobari-Bonab B, Jalil-Abkenar SS. Adaptation of positive parenting program training based on cultural values and evaluation of its effectiveness in psychological health and interaction of mother with slow paced children. $J$ Research \& Health2019; 9(4): 284- 293.

\section{Introduction}

The main mission of softhearted and soothing spouses is to achieve the highest goal of marriage, namely attainment to a stable and long-lasting peace. Parenting in the religious culture includes prayer, orison, planning, and fruition of training thoughts and perfectionseeking in the light of cultural values and instructions [1]. In this regard, one of the important factors in developing and spreading

\begin{abstract}
Mental impairment has undesirable effects on the all aspect of individual's life, while the use of parenting programs has been associated with beneficial outcomes. The aim of this research was the adaptation of a positive parenting program (Triple-P) training based on the cultural values and evaluation of its effectiveness in psychological health and interaction of mother with slow paced (SP) children. This research was a semi-experimental study designed as pretest-posttest using control group. The magnitude of 40 mothers of students with SP participated in this study. They were selected according to the random cluster sampling method from exceptional schools of Tehran provinces. The participants were divided into two groups; each group consisted of 20 participants. The experimental group received Triple-P training in twelve 90-minute sessions, while no intervention was carried out on the control group. The instruments of present research were general health questionnaire and parent-child relationship scale. The results of MACNOVA showed that Triple-P had a positive significant effect on the psychological health and interaction of mothers with SP children. Since parenting skills training can lead to the enhanced psychological health and improved motherchild interaction, planning for Triple-P training based on cultural values has particular importance.
\end{abstract}

Keywords: Child, Health, Interaction, Psychological facilities for the exceptional children education is the extension of knowledge and awareness and amenability of mothers and fathers toward the children [2,3]. Taking attention into the cognition and education of exceptional children and students, individuals who cannot be favorably benefited from normal education programs for specific reasons of physical, mental, emotional, and 
psychological, is a sign of progress, originality, and richness of culture and education system in a society. Among the exceptional children, slow paced (SP) children and students have considerable situation because of the special complexity of intelligence phenomenon [2].

The birth and care of SP child confront the family with many problems [4] because the quantity and quality of parent relationships and family member interactions could harm the psychological health and family performance [5]. SP is a disorder in the development process that creates significant limitations both in intellectual functioning and adaptive behavior as expressed in conceptual, social, and practical adaptive skills. SP children acquire language by little delay, but they speak good enough to manage their life. Most of them are able to live on their own; however, their self-care skills may develope later than normal children. When try to learn reading and writing, the poor intelligence is evident in them. So, they can finally acquire these skills, but with slower steps and lower degrees than their normal peers. They can live independently but may have difficulties in performing daily roles. Inappropriate conditions of familial environment such as parenting style have undesirable effects on SP children [2]. Since childhood is of the most important stages of life and personality of individual is formed during this period [6], it is not far from expectation that parent-child relationship is considered as one of the most effective factors in mental and social growth of any child [7]. Family is an innate, natural, alone, and eternal institution in society and is the main medium for the personality of a child to develop. In the celestial worldview, the child is a fiducially gift donated from kindness and boon of god to parents [1]. Therefore, quality of parent-child relationships in the primary years of childhood makes a basis for cognitive, social, and emotional growth in the next stages of life [7]. Indeed, mother affective care of child prepares a situation that child finds him/her self amiable and expects others to pay attention to him/her as a valuable entity. In addition to positive effects of a healthy relationship, we cannot be aware of negative effects of an inadequate and unhealthy relationship. Among the negative effects are the over rate of psychological health problems in parents and parent-child mutual relationship [8]. Hayes et al. believed that behavioral problems of children in life primary years have relationships with negative behavior, interaction, and stress of mother. So, problematic behavior of child resulted from this situation can lead to the reduction in the level of psychological health in parents [9].

The relationship of softhearted and soothing spouses is the lovers relationship, body and cloth relationship, integrity attendance relationship and it signify to kindness that refers to the paradigm 158 of Baghareh sura "they are an apparel for you and you are an apparel for them" [1]. Several factors are effective in psychological health of parents and their relationships with SP children that require different instructional methods and programs [10] that Positive Parenting Program (Triple-P) training based on cultural values is one of these interventions [11]. Triple-P training is one of instruction methods for parents, which has been developed according to familial behavior therapy based on social learning principles of Bandura [11-13]. This program with offering information about various needs of mother and child, motherchild relationship, family performance, and parenting skills can be used for alleviating behavioral and emotional problems in child and promoting quality of mother-child relationship $[14,15]$ in a way that enrich protecting factors in children and decrease risk factors related to behavioral and emotional problems in children [11]. The use of Triple-P training has been recommended for parents of children with special needs from birth to 16 years and focused on psychological health, management, and control of behavior and relationship with child. In this program it is possible to make the sense of social competency and self-control in parents through mothers training for promotion of children development skills [16,17]. This 
program seeks the following goals: increase of knowledge, skill, self-confidence, self-efficacy and brainy of parents in child training, provide treatment by instructional learning, problemsolving ability to middleman modeling and structured treatment of problem-solving, spreading entertainment, safety, and creating an environment with minimum conflicts to children, increasing psychological health, efficiency of behavioral, intellectual, language, affective, and social in children through Triple-P [15].

Children with SP experience many problems in the lifespan and during different stages of growth [4]. However, many researches and studies for identifying and solving these problems have been provided solutions of therapeutic, educational, and rehabilitating, but not means that all problems for this individuals can be pre-identified and appropriate programs be administrated to solve them [18]. A familybased intervention that has gained a great reputation and is fruition of strong scientific support in areas such as psychological health, interaction in family, reduction of behavior problems, marital satisfaction, attachment styles, and parenting styles has been named Triple-P positive parenting program [13]. Fujiwara et al. [11] conducted an experimental research with pretest and posttest design and a control group to investigate the effectiveness of group-based familial interventional program, which is known as Triple-P, in the reduction of behavioral problems in children, changing inappropriate functions of parenting, and parents' adjustment in the Japanese families. They divided the participants into intervention and control groups consisted of 91 and 24 subjects, respectively. The findings indicated the reduction of parenting undesirable functions, depression and stress, perceived parenting problems in parents, child behavioral problems and promotion of parent confidence in Japanese families. The study results of Chu et al. [19] showed that parenting programs according to the public health approach led to the significant increase of mental health in parents of adolescents. The research results of Metzler et al. [20] indicated that the use of mass media in educating and making interventions in parenting skills with regard to the prevention approach can lead to a significant increase in parents support and their mental health. Jalali et al. [21] in an experimental research with pretest-posttest design and control group paid to investigate the effectiveness of Triple-P on psychological health in mothers of children with oppositional defiant disorder. The findings of this study showed a significant increase in psychological health in mothers of children with oppositional defiant disorder. Abedi-Shapourabadi et al. [22] in a research paid to investigate the effectiveness of group Triple-P in parent-child relationship in children with attention deficit/hyperactivity disorders. Results of this study showed that training of this group program to mother's lead to a significant decrease in conflicts and dependency, and promotion of closeness and mother-child relationship. In another research, Abarashi et al. [23] paid to investigate the impact of psychosocial child development training program through improvement of mother-child interaction in parental selfefficacy and relationship between mother and child. Results indicated that psychosocial child development training program had positive significant effects on parental selfefficacy. Positive relationship of mother-child was promoted in the areas of relations and dependency, but there was not significant increase in other areas such as conflicts and closeness. In conclusion, there was not significant increase in positive relationship of mother-child. The effectiveness of Triple-P has been confirmed for treatment of behavioral problems [13,16,17,24-26] and ineffective parenting styles of parents [25,27-30].

The results of previous studies showed that Triple-P training has positive effects on improving the interactions in the family, behavioral problems, and parenting styles for children with special needs, but no research was found in the field of psychological health of mothers of children with SP and interaction of mother-child. While, the parents of children 
with SP are likely to face many problems in these areas, because in many cases, parents of children with SP are disabled in employing the parenting skills and they need parenting program trainings based on their cultural values. In this regard, by adaptation of Triple-P training based on Iranian cultural values and indigenization and administration of this program on mothers of children with SP, we can understand the effectiveness of such trainings in areas such as psychological health and motherchild interaction; understand the necessity of the design in application and covering the research gape in this area. This approach has been ignored in many interventions. What that highlights the importance of this study is the sensitivity of working with parents of children with SP. It is likely that parenting instruction that considers these key points may play an important role in psychological health and interaction of mother with SP child and make this issue more evident. The aim of the present study was to adapt Triple-P training based on cultural values and evaluate its effectiveness in psychological health and interaction of mother with SP child.

\section{Method}

The present research was a semi-experimental study with pretest- posttest design and a control group. Statistical population included all mothers of SP students aged 28 to 45 years old that their children were studying in first to third grade in exceptional elementary schools of Tehran provinces during. The participants were selected from two exceptional schools located in two cities of Tehran provinces through random cluster sampling method. Then, 40 mothers of students with SP were selected randomly by using table of random numbers with respect to inclusion criteria (age range of 28-45 years old and living with husband) and exclusion criteria (currently participating in similar training programs; involving in a child with any type of sensory, physical, or mobility impairments except for SP child, and consuming stimulant drugs by the child). In the next stage, the participants by using the table of random numbers without replacement were divided into two groups (experimental and control groups), each consisted of 20 participants. Because of the employed semi-experimental method, the minimum required sample size was 15 for each group. Pay attention to formula $\left(\delta^{2}=22.082, \quad \mathrm{Z}_{1-\alpha / 2}=1.96, \mathrm{~d}=12\right) \quad[31]$ was determined sample size about 18 participants. However the sample size was determined 20 participants, because of possibility of dropout of the subjects during the study. However, the obtained results should be generalized cautiously.

Assigning the names of experimental and control into the groups was carried out randomly by drawing. In this method, the names of experimental group and control group were written on the slips of a paper. Then, the slips were withdrawn from a container as a lottery. The experimental group received Triple-P training based on cultural values in 12 sessions, while the control group did not. Prior to the intervention, the research procedure was explained to the school authorities and informed consent was obtained from all the participants. The instruments of this research were general health questionnaire (GHQ) and parent-child relationship scale (PCRS).

The GHQ was made by Goldberg and Hiller in 1979, which consists of total 28 items in 4 subscales (somatic symptoms, anxiety, depression, and social dysfunction). Each subscale has 7 items. The questionnaire is scored based on Likert scale from zero (more than ever) to 3 (much worse than ever). Total score of twenty-three or higher (cut of point) is the sign of lack of mental health. Goldberg reported reliability and validity of the questionnaire as 0.89 and 0.83 , respectively. In Iran, Yaghobi et al. reported the reliability of the GHQ as 0.88 in test-retest method and the validity of subscales as 0.55 [32].

PCRS was made by Pianta in 1994, which consists of 33 items to assess the parent's perception of their relationship with their child. This scale consists of the subscales of conflict (17 items), closeness (10 items), dependency (6 items), and positive general 
interaction (total subscales). This instrument scored by 5-point rating scale ranging from 1 (definitely does not apply) to 5 (definitely applies). This questionnaire has been translated by Tahmasian and the content validity has been assessed by experts. Content validity and reliability of this questionnaire was obtained via Cronbach's alpha. Reliability of conflict, closeness, dependency and positive general interaction subscales were reported as 0.84 , $0.70,0.61$, and 0.86 , respectively [23].

In the first stage of research, after subject selection, the importance of research was explained to principals and mothers in an ethical manner. The mothers were asked to give informed consent. Then, subjects were divided by replacement into two groups (experimental and control groups), each group consisted of 20 individuals. To assess psychological health and relationships of mother with SP child, GHQ of Goldberg and Hiller and PCRS of Pianta were employed in pretest. Then, experimental group participated in twelve 90-minute intervention sessions (each session per week). One psychologist of exceptional children trained Triple-P based on cultural values by use of group discussion, cooperative learning, and role playing methods to the experimental group, while the control group was not included in the intervention. The session content was adapted and validated by Delphi method in four rounds. Delphi method is a systematic approach in research to exploit the opinions of a panel of expertsabout a subject. In this method, it is possible to reach to the expert consensus via administrating questionnaires in consecutive rounds with anonymously repliers and delivering feedback to panel members. The proficiency of research group in the development of navigation stages and instrument adaptation guaranties the program formal validity. In this regard, the members contributed in the program adaptation were five experts in the area of $\mathrm{SP}$ children with $\mathrm{PhD}$ degree in psychology of exceptional children and five teachers of family instruction with at least M.A degree in psychology of exceptional children. These contributors were representatives of group or relevant knowledge area and they approved the content validity of the program. In the present parenting program, special attention has been given to psychological health of mothers. That was because we should not expect desirable results if we ignore psychological health. On the other hand, psychological health has special role in the Triple-P training based on cultural values. The content of Triple-P training based on cultural values, which was received by experimental group, is described as follows.

The first session (promoting mental health for parenting): welcoming to participants, explaining the group rules, introducing the program and sessions structure, expressing verbal perceptions, self-efficacy, family selfsufficiency and sense of well-being. The second session (promoting mental health for parenting): self-worth, self-confidence, and promoting social performance. The third session (promoting child development): introducing the bases of the parenting program, characterization of children of target, children expectations, attitude definition, shaping and modification of attitudes in target group. The forth session: methods of promoting desirable behavior (positive reinforcement, negative reinforcement, tokeneconomy, and contingency contracting). The fifth session: methods of creating desirable behaviors (shaping and chaining). The sixth session: methods of sustaining and expanding desirable behaviors (continuous reinforcement and intermittent reinforcement). The seventh session: positive methods of decreasing undesirable behaviors (differential reinforcement of low rates of behavior, differential reinforcement of other behavior, differential reinforcement of incompatible behavior, satiation). The eighth session: negative methods of decreasing undesirable behaviors (extinction, time out, response cost, restitution, punishment). The ninth session: challenges and methods of controlling children's behavior, unwanted mutual impression of parent-child behaviors. The tenth session: pathology of family based on cultural values. The eleventh session: 
family importance based on cultural values. The twelfth session: Triple-P based on cultural values.

In the final stage of research, the experimental and control groups were assessed by administrating GHQ of Goldberg and Hiller and PCRS of Pianta as posttest. The data were analyzed by multivariate analysis of covariance in SPSS software (version 22, SPSS Inc., Chicago, IL).

\section{Results}

Descriptive findings indicated subject's age in the range of 28 to 45 years old with mean age of $38.67 \pm 5.05$. The obtained P-values showed that the observed difference between the scores of pretest and posttest in the GHQ and PCRS was not because of the difference between subject's age $(p=0.129)$. Table 1 represents descriptive indices of GHQ in four subscales (somatic symptoms, anxiety, social dysfunction, and depression) and PCRS in four subscales (conflict, closeness, dependency, and positive general interaction) in pretest and posttest of experimental and control groups.

Table 1 Descriptive indices of experimental and control groups in pretest and posttest

\begin{tabular}{|c|c|c|c|c|c|c|}
\hline & \multirow[t]{2}{*}{ Variable } & \multirow{2}{*}{ Situation } & \multicolumn{2}{|c|}{$\begin{array}{l}\text { Experimental } \\
\text { group }\end{array}$} & \multicolumn{2}{|c|}{ Control group } \\
\hline & & & Mean & SD & Mean & SD \\
\hline \multirow{10}{*}{ GHQ } & \multirow{2}{*}{ Somatic symptoms } & Pretest & 9.45 & 0.66 & 9.40 & 0.88 \\
\hline & & Posttest & 8.20 & 1.13 & 9.45 & 0.97 \\
\hline & \multirow{2}{*}{ Anxiety } & Pretest & 13.55 & 1.43 & 13.55 & 1.06 \\
\hline & & Posttest & 10.50 & 1.01 & 13.55 & 1.33 \\
\hline & \multirow{2}{*}{ Social dysfunction } & Pretest & 11.05 & 1.87 & 11.10 & 0.86 \\
\hline & & Posttest & 9.90 & 1.90 & 11.05 & 0.87 \\
\hline & \multirow{4}{*}{$\begin{array}{l}\text { Depression } \\
\text { Total mental health }\end{array}$} & Pretest & 11.40 & 0.98 & 11.50 & 1.22 \\
\hline & & Posttest & 9.25 & 0.95 & 11.45 & 1.07 \\
\hline & & Pretest & 45.45 & 1.66 & 45.55 & 1.55 \\
\hline & & Posttest & 37.85 & 1.72 & 45.50 & 1.42 \\
\hline \multirow{8}{*}{ PCRS } & \multirow{2}{*}{ Conflict } & Pretest & 35.65 & 1.92 & 35.45 & 1.63 \\
\hline & & Posttest & 46.65 & 2.01 & 35.70 & 2.25 \\
\hline & \multirow{2}{*}{ Closeness } & Pretest & 20.40 & 1.81 & 20.55 & 1.46 \\
\hline & & Posttest & 26.30 & 1.34 & 20.75 & 1.33 \\
\hline & \multirow{2}{*}{ Dependency } & Pretest & 10.80 & 1.51 & 10.35 & 0.98 \\
\hline & & Posttest & 15.51 & 0.82 & 10.55 & 0.94 \\
\hline & \multirow{2}{*}{$\begin{array}{l}\text { Positive general } \\
\text { interaction }\end{array}$} & Pretest & 66.85 & 2.94 & 66.10 & 1.51 \\
\hline & & Posttest & 88.45 & 2.64 & 67.05 & 2.30 \\
\hline
\end{tabular}

Because of the presence of one independent variable and several dependent variables and moderate effect of pretest, multivariate analysis of covariance (MANCOVA) was used to analyze the data [31]. After checking and confirming the normality of research variables, Box's test approved the assumption of equality of variance-covariance $(p>0.05)$. Also, the assumption of variance equality by using Leven's test was confirmed ( $\mathrm{p}>0.05$ ). So, using the ANCOVA test is allowable. GHQ and PCRS were calculated via Wilk's Lambda test and the outputs showed that experimental and control groups had significant differences at least in one variable with eta square $(\eta 2)$ of $\% 89$ $(\mathrm{F}=440.69, \mathrm{p}=0.001)$. In order to determine this difference, MANCOVA test was used and the results are presented in Table 2 .

In this analysis, pretest variable is moderated because of correlation with posttest. According to Table 2, group type had a significant effect on posttest scores $(\mathrm{p}<0.05)$. According to eta square $(\eta 2)$, it can be concluded that $28 \%$, $58 \%, 49 \%, 39 \%$, and $53 \%$ of variances in the variables of somatic symptoms, anxiety, social dysfunction, depression, and total mental 
health of GHQ, respectively, are related to the effectiveness of Triple-P training based on cultural values on psychological health of mother with SP children. Also, in the variables of conflict, closeness, dependency, and general positive interaction of PCRS, it can be explained that $62 \%, 63 \%, 64 \%$, and $67 \%$ of variances, respectively, are related to the effectiveness of intervention program in the mother interaction with SP children.

Table 2 Results of MANCOVA in GHQ and PCRS

\begin{tabular}{llcccccc}
\hline & Dependent variable & SS & df & MS & F & p & $\eta 2$ \\
\hline \multirow{6}{*}{ GHQ } & Somatic symptoms & 5.68 & 1 & 5.68 & 11.85 & 0.003 & 0.28 \\
& Anxiety & 32.40 & 1 & 32.40 & 42.13 & 0.005 & 0.58 \\
& Social dysfunction & 14.73 & 1 & 14.73 & 29.39 & 0.005 & 0.49 \\
& Depression & 6.72 & 1 & 6.72 & 19.22 & 0.005 & 0.39 \\
& Total mental health & 62.38 & 1 & 62.38 & 101.19 & 0.002 & 0.53 \\
& Conflict & 1040.91 & 1 & 1040.91 & 443.02 & 0.001 & 0.62 \\
& PCRS & 296.67 & 1 & 296.67 & 494.16 & 0.001 & 0.63 \\
& Closeness & 209.42 & 1 & 209.42 & 559.32 & 0.001 & 0.64 \\
& Dependency & 4074.61 & 1 & 4074.61 & 1457.10 & 0.001 & 0.67 \\
\hline
\end{tabular}

\section{Discussion}

The research findings indicated that adapted Triple-P training based on cultural values had a positive significant effect on psychological health of mothers with SP children in the dimensions of somatic symptoms, anxiety, social dysfunction, depression, and total mental health. Also, this intervention program had a positive significant effect on the interaction of mother with SP child in the dimensions of conflict, closeness, dependency, and general positive interaction.

A part of research findings that indicated the effectiveness of adapted Triple-P training based on cultural values on psychological health of mothers with SP children were in agreement with the data obtained by Chu et al. [19] on the positive significant effect of Triple-P training on psychological health of parents. The findings also are consistent with the research results of Metzler et al. [20] that showed the mass media influence in increasing parent support and mental health of parents via parenting training interventions. Also, our results were in accordance with the research results of Hanna, Edgecombe \& Jackson [33] that indicated the effectiveness of parenting skills training and development of communication and social support in psychological health of parents. Moreover, they were in agreement with the findings of Jalali et al. [21] that showed the effectiveness of Triple-P training on psychological health of mothers of children with oppositional defiant disorder; and with the results of Roushanbin, Pouretemad \& Khoushabi [27] that reported the effect of group Triple-P training on decreasing parenting stress and increasing psychological health of mothers.

For explanation of these findings, it can be said that mothers of SP children suffer problems in interpersonal relationships and their psychological health is under threat because of challenging behaviors of their SP children and low cooperation of father in affairs of SP child [34]. In adapted Triple-P training based on cultural values we discussed in group sessions on parent concerns in etiology, treatment, and prognosis of children disorder and mothers received essential information and support from the others. Also, the increased knowledge makes the parents more aware of problems of SP children and the training program helps them to improve their behavior management skills and subsequently their selfefficacy which all resulted in the promotion of psychological health $[9,14]$. On the other hand, this intervention program is focused on mother's self-efficacy in managing and controlling the behavior. Hence, a sense of social competency and self-control is created 
in mothers via learning child development skills $[16,17]$. Therefore, the promoted psychological health is not far from expectations.

Another part of results of the present research showed that Triple-P training had a positive effect on interaction of mother with SP child in the dimensions of conflict, closeness, dependency, and general positive interaction. These findings were consistent with the research findings of Fujiwara et al. [11] that proved the effectiveness of Triple-P training in the reduction of parenting undesirable performance, depression, stress, perceived problems of parenting in parents, behavior problems of children and the promotion of parent confidence. These results were in agreement with the study results of Abedi-shapourabadi et al. [22] that showed the effectiveness of group Triple-P on mother-child relationship which resulted in the significant decrease of conflict and dependency, and promotion of closeness and mother-child relationship. Also, they are in accordance with the research results of Abarashi et al. [23] that showed the influence of psychosocial child development training program on mother-child relationship in the areas of dependency and positive interaction, but not consistent with the results obtained in other areas such as decreasing conflict and increasing closeness. Moreover, the results of present research were in agreement with the data of many studies on the effectiveness of Triple-P training based on cultural values in parenting styles of parents [25-30].

to explain the inconsistent findings, it can be said that participants in the study of Abarashi et al. were 18 mothers in experimental group and 25 mothers in control group that were selected voluntarily from kindergartens. Their children were under three years and they only received training in 6 sessions, but experimental and control groups in the present research consisted of 20 individuals in each group that were selected randomly, received training in 12 sessions, and their children aged 6 to 9 years old. It is possible that the difference in magnitude of individuals in experimental and control groups, sampling method, number of training sessions, and age range of children has influenced the obtained results. Moreover, in the research of Abarashi et al. mothers with normal children were participated and they had no special problem in the interaction with their child, but in the present research mothers with SP children participated and they had many problems in the interaction with their child. These factors may have much contribution in the inconsistency of results obtained in the two researches.

For explanation of consistent findings of previous researches with our findings, it can be said that the care of SP child confronts family with many problems [4]. The children with SP can affect the quantity and quality of parent relationships and family member's interactions and can be harmful to family performance [3]. On the other hand, Triple-P training that has been created according to familial behavior therapy on the basis of social learning of Bandura $[12,13]$ by offering valuable information about various needs of mother and child, motherchild relationship, family performance and parenting skills can be employed for reducing behavioral and emotional problems in child and quality promotion of mother-child relationship $[14,15]$. Therefore, it is likely that Triple-P training based on cultural values exhibits a desirable effect on the interaction of mother with SP child in the areas of conflict, closeness, dependency, and general positive interaction.

\section{Conclusion}

The SP child can affect all the aspects of individual's life, especially psychological health and mother-child interaction. The use of parenting programs has been associated with desirable outcomes on the promotion of psychological health and mother-child interaction. So, special instructional and rehabilitation programs based on cultural values and beliefs are needed. Also, the program should be adapted and by giving a positive view to parenting, result in the desirable outcomes, or scilicet, better developed psychological health and interaction of mother with SP child. The psychological health and mother interaction with child is a complex and multi-dimensional phenomenon 
that is defined in the light of interaction of many factors such as attitude and acceptance rate of parents, management method and behavior control, sense of social competency and selfcontrol, parenting knowledge and skills, selfconfidence and brainy of parent in child training and making an environment with minimum conflicts, quality of parent-child relationship, mother affective care of child, psychological health of parent and interactional and multi-layer relationships of parent and children. Attention to these factors is necessary, because these factors have very important role in psychological health of mothers in the areas of somatic symptoms, anxiety, social dysfunction, depression, and influence the interaction of mother with SP child in the areas of conflict, closeness, dependency, and general positive interaction. Therefore, those parent training programs that have positive view in parenting based on cultural values and take these key factors into account, would positively affect psychological health and interaction of mother-child.

The present research was faced with methodological limitations such as limitations related to the special group of mothers with SP children and special instrument for the assessment of psychological health and interaction of motherchild. Also, with respect to the low volume sample size, limitation of research method and other effective factors, the generalization of results should be carried out cautiously. Another limitation was the lack of enough time to followup the results in long-term.

For further researches it is recommended that other studies be carried out on other exceptional children with different age range seeking for the effect of other factors. It is also suggested for other cognitive and meta-cognitive intervention programs with different patterns of familybased, school-based and community-based to be designed and administrated to provide opportunity for follow-upping the results.

\section{Acknowledgments}

Authorswouldliketoappreciatetheadministration for exceptional children education in Tehran Province. Also, we respectfully appreciate all the parents of children participated in the research and all the dears that assisted us in the research administration. This paper derived from the $\mathrm{PhD}$ dissertation of Tehran University.

\section{Authors' contributions}

Study design: MA, GHAA, AAA, MPT

Data collection and analysis: BGH, MA

Manuscript preparation: MA

All authors have read and approved the final version

\section{Conflict of Interest}

"The authors declare that they have no competing interests."

\section{Funding}

The author (s) received no financial support for the research, authorship and/or publication of this manuscript.

\section{Availability of data and materials}

The datasets used and/or analyzed during this study are available from the corresponding author on reasonable request.

\section{References}

1- Afrooz GHA. Psychology of marriage and the glory of being a spouse. 2nd ed. Tehran: Tehran university publications; 2013.

2- Afrooz GHA. Introduction on the psychology and exceptional children education. 28th ed. Tehran: Tehran university publications; 2011.

3- Hallahan DP, Kauffman JM, Pullen PC. Exceptional learners: an introduction to special education. USA, Boston: Allyn \& Bacon; 1997.

4- Van Bysterveldt AK, Westerveld MF, Gillon G, Foster-Cohen S. Personal narrative skills of schoolaged children with down syndrome. Int J Lang Commun Disord2012; 47(1): 95-105.

5- Behpajooh A. Family and children with special needs. Tehran: Avaye Noor publications; 2010.

6- Cartwright-Hatton S, McNally D, White C, Verduyn C. Parenting skills training: an effective intervention for internalizing symptoms in younger children? J Child Adolesc Psychiatr Nurs2005; 18(2): 45-52.

7- Mantymaa M. Early mother-infant interaction. [dissertation]. Department of psychology. Tampere: University of Tampere, Medical School 2006; pp:160.

8- Barlow J, Parsons J, Stewart-Brown S. Preventing emotional and behavioural problems: the effectiveness 
of parenting programmes with children less than 3 years of age. Child Care Health Dev2005; 31(1): 33-42.

9- Hayes L, Matthews J, Copley A, Welsh D. A randomized controlled trial of a mother-infant or toddler parenting program: demonstrating effectiveness in practice. J Pediatr Psychol2007; 33(5): 473-86.

10- Cooper M, Watson JC, Hoeldampf D. Person-centered and experiential therapies work: a review of the research on counseling, psychotherapy and related practices. UK, Ross-on-Wye: PCCS Books; 2010.

11- Fujiwara T, Kato N, Sanders MR. Effectiveness of group positive parenting program (Triple $\mathrm{P}$ ) in changing child behavior, parenting style, and parental adjustment: an intervention study in Japan. J Child Fam Stud2011; 20(6): 804-13.

12- Turner K, Markie-Dadds C, Sanders M. Facilitator's manual for group Triple P (Rev. ed.). Australia, Brisbane: Triple P International; 2002.

13- Sanders MR, Stallman H, McHale M. Workplace Triple P: a controlled evaluation of a parenting intervention for working parents. J Fam Psychol2011; 25(4): 581-90.

14- Sanders MR. Triple p-positive parenting program as a public health approach to strengthening parenting. $J$ Fam Psycho2008; 22(4): 506-17.

15- Sanders MR. Triple p-positive parenting program: a population approach to promoting competent parenting. Australian e-Journal for the Advancement of Mental Health2003; 2(3): 127-43.

16- Sanders MR, Woolley ML. The relationship between maternal self-efficacy and parenting practices: implications for parent training. Child Care Health Dev2005; 31(1): 65-73.

17- Leung C, Sanders MR, Leung S, Mak R, Lau J. An outcome evaluation of the implementation of the triple p-positive parenting program in Hong Kong. Fam Process2003; 42(4): 531-44.

18- Humphry R, Case-Smith J. Workings with families. In Case-Smith J, ed. Occupational therapy for children. 5th ed. USA: St Louis: MO: Elsevier Mosby; 2005. pp: 117-53. 19- Chu J, Farruggia S, Sanders MR, Ralph A. Towards a public health approach to parenting programs for parents of adolescents. Journal of Public Health2012; 34(1): 41-7. 20- Metzler C, Sanders MR, Rusby J, Crowley RN. Using consumer preference information to increase the reach and impact of media-based parenting interventions in a public health approach to parenting support. Behav Ther2012; 43(2): 257-70.

21- Jalali M, Pourahmadi E, Tahmasian K, Shaeiri MR. The effectiveness of the triple $\mathrm{p}$-positive parenting program on psychological well-being of mothers of children with Oppositional Defiant Disorder (ODD). Journal of Family Research2008; 4(4): 353-68.

22- Abedi-Shapourabadi A, Pourmohamadreza-Tajrishi M,
Mohamad KP, Farzi M. Effectiveness of group training positive parenting program (Triple-P) on parent-child relationship in children with attention deficit/ hyperactivity disorders. Journal of clinical Psychology2012; 3(15): 63-75. 23- Abarashi Z, Tahmasian K, Mazaheri MA, Panaghi L. The impact of psychosocial child development training program, done through improvement of mother-child interaction, on parental self-efficacy and relationship between mother and child under three. Journal of Research in Psychological Health2009; 3(3): 49-57.

24- Pourahmadi E, Jalali M, Roshan R, Abedin A. The effect of positive parenting training program in reducing children somatoform disorders. Journal of Baboul University of Medical Sciences2002; 11(2): 74-94.

25- Jalali M, Pourahmadi E, Babapour KH, Shaeeri M. The effect of positive parenting training program in reducing symptoms in children with externalizing disorders. Tabriz University Psychology Quarterly2007; 13: 15-36.

26- Sanders MR, Markie-Dadds C, Tully LA, Bor W. The triple p-positive parenting program: a comparison of enhanced, standard, and self-directed behavior family intervention for parents of children with early onset conduct problems. J Consult Clin Psychol2000; 68(4): 624-40.

27- Roushanbin M, Pouretemad HR, Khoushabi K. The effect of group positive parenting program training on parenting stress in mothers of ADHD children aged 4-10 years old. Family Research Quarterly2007; 3(10): 555-72. 28- Sanders MR, Pidgeon AM, Gravestock F, Connors MD, Brown S, Young RW. Does parental attributional retraining and anger management enhance the effects of the Triple P-Positive Parenting Program with parents at risk of child maltreatment? Behav Ther2004; 35(3): 513-35.

29- Sanders MR, McFarland MC. Treatment of depressed mothers with disordered children: Acontrolled elevation. Behav Ther2006; 31(1): 89-112.

30- Oord SVD, Bogels SM, Peijnenburg D. The effectiveness of mindfulness training for children with ADHD and mindful parenting for their parents. $J$ Child Fam Stud2012; 21(1): 139-47.

31- Gall M, Borg W, Gall j. Quantitative and qualitative methods of research in psychology and educational science. Translate by Nasr A, Arizi H, Abolghasemi M, et al. Tehran: Samt Publication; 2003.

32- Ashori M, Pourmohamadreza-Tajrishi M, JalilAbkenar SS. The effectiveness of emotional intelligence training on the mental health of deaf students. Iran $J$ Public Health2013; 42(10): 1174-80.

33- Hanna B, Edgecombe G, Jackson S. The importance of first-time parent groups for new parents. Nurs Health Sci2002; 4(4): 209-14.

34- Bostrom P. Experiences of parenthood and the child with an intellectual disability. [dissertation]. Department by psychology. University of Gothenburg 2012; pp:75.

\footnotetext{
Copyright $(\mathrm{C} 2016$ ASP Ins. This open-access article is published under the terms of the Creative Commons Attribution-NonCommercial 4.0 International License which permits Share (copy and redistribute the material in any medium or format) and Adapt (remix, transform, and build upon the material) under the Attribution-NonCommercial terms.
} 